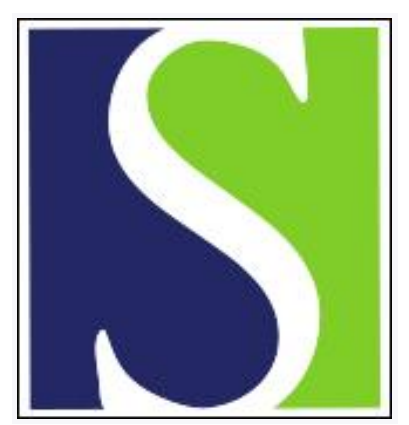

Scand J Work Environ Health 2001;27(5):318-326

https://doi.org/10.5271/sjweh.620

Issue date: Oct 2001

Excessive fatigue and weight gain in cleanroom workers after changing from an 8-hour to a 12-hour shift

by Yamada Y, Kameda M, Noborisaka Y, Suzuki H, Honda M, Yamada S

Affiliation: Department of Hygiene, Kanazawa Medical University. Diagaku, Uchinada, Ishikawa, 920-0293 Japan. u1yamada@kanazawa-med.ac.jp

Refers to the following text of the Journal: 1999;25(2):100-104

The following articles refer to this text: 2007;33(1):45-50; SJWEH

Supplements 2008;(5):14-21; 2013;39(3):221-232;

2013;39(3):241-258

Key terms: 12-hour shift; 8-hour shift; body weight; cleanroom worker; compressed work; excessive fatigue; psychological health; shift work; weight gain; work stress

This article in PubMed: www.ncbi.nlm.nih.gov/pubmed/11712612

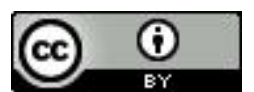




\title{
Excessive fatigue and weight gain among cleanroom workers after changing from an 8-hour to a 12-hour shift
}

\author{
by Yuichi Yamada, MD, ${ }^{1}$ Maki Kameda, ${ }^{2}$ Yuka Noborisaka, MD, ${ }^{1}$ Hisa Suzuki, MD, ${ }^{1}$ Maki Honda, ${ }^{2}$ \\ Seiji Yamada, $M D^{3}$
}

\begin{abstract}
Yamada $\mathrm{Y}$, Kameda M, Noborisaka Y, Suzuki H, Honda M, Yamada S. Excessive fatigue and weight gain in cleanroom workers after changing from an 8-hour to a 12-hour shift. Scand $J$ Work Environ Health 2001;27(5):318-326.
\end{abstract}

\begin{abstract}
Objectives This study attempted to clarify the health effects of implementing a 12-hour shift in place of the traditional 8-hour shift in work in a clean room in an electronic parts producing factory.

Methods Health-check records during a year or longer before and after the shift change were reviewed regarding subjective symptoms, height, body weight, and blood pressure for 189 male workers who had moved to a 12-hour shift and for 16 male workers who remained on an 8-hour shift.

Results The workers changing to a 12-hour shift showed significant increases in subjective symptoms, particularly psychological symptoms defined as related to fatigue and bodyweight gain, $1 \mathrm{~kg}$ on average, in the year after the shift change. Increased symptoms and body weight remained high even another year later. The workers remaining in the 8-hour shift did not show significant changes in symptoms or body weight during the observation. No changes in blood pressure were observed in relation to the shift move.

Conclusions The results suggested that implementing a 12-hour shift caused marked psychological fatigue and unhealthy weight gain among some cleanroom workers and that the adaptation to the new work shift did not seem easy for these workers. Working in a clean room can be considered a job in which special caution is needed regarding increased fatigue when a compressed working schedule is implemented. Attention should also be paid to possible weight gain among persons working 12-hour shifts.
\end{abstract}

Key terms body weight, compressed work, psychological health, shift work, work stress.

Recent economic and social pressures have prompted many workplaces to introduce 12-hour shift work instead of traditional 8-hour shifts. It has been debated whether the 12-hour shift is better than the traditional 8-hour shift for health and safety, as well as for job performance and the social well-being of workers. Recently, Smith et al (1) extensively reviewed previous studies comparing the effects of 8-and 12-hour shifts. According to them, although some studies have claimed disadvantages of the longer 12-hour work, such as severe fatigue, sleep disturbances, and social life impairment, many other recent studies have reported beneficial aspects of 12-hour shifts, mainly more active family and social life thanks to the longer off-duty time, without apparent adverse effects on worker health. Thus they concluded that, although the study results have been generally equivocal, 12-hour shift work seems to harm the health and life of workers less or at most equally in comparison with 8-hour shift work. However, they also pointed out that problems with sleep, health, and well-being when working 12-hour shifts depended largely on the work conditions, the nature of the job, and the way the system was implemented among the workforce, and they thus called for further longitudinal comparative research into the chronic impact of such compressed work.

In an electronic parts producing factory located in a suburban area in Japan, the company proposed the introduction of 12-hour shifts to the workforce instead of the 8-hour shifts that had been the norm for 10 years or

1 Department of Hygiene, Kanazawa Medical University, Uchinada, Ishikawa, Japan.

2 Health Service Station, Panasonic Liquid Crystal Display Division, Kawakita, Ishikawa, Japan.

3 Matsushita Science Center of Industrial Hygiene, Osaka, Japan.

Reprint requests to: Dr Yuichi Yamada, Department of Hygiene, Kanazawa Medical University. Diagaku, Uchinada, Ishikawa, 920-0293 Japan. [E-mail: u1yamada@kanazawa-med.ac.jp] 
longer so as to enhance production efficacy. The workers' union accepted the change from 8-hour to 12-hour shifts as a temporary trial before a formal agreement with the company was reached because of fear of an excessive load on the workers. A series of attempts was then conducted around August 1997 when the 12-hour shift was implemented in the factory to develop measures to support and promote the health of the 12-hour shift workers, such as improving operational and environmental work conditions, facilities for rest and catering services and shift designs. In this context, we analyzed data on subjective symptoms, height and body weight, and blood pressure in periodic health checks conducted in this factory during a year or longer before and after this change, aiming to clarify the effects of the change from 8-hour to 12 -hour shifts on worker health.

\section{Subjects and methods}

The production of electronic parts, liquid crystal displays, is performed within clean air rooms. The workers need to wear special clothes, cap, mask, gloves, and shoes and to go through air shower gates whenever entering the workplaces. Their work consists of operating and maintaining automatic processing machines and light manual labor such as carrying and supplying materials (mainly glass plates) to the machines, or detecting and repairing minor defects in the products using machines with a video display apparatus, or finishing and wrapping the products. The workers rotate these jobs in 3- or 4-month periods. Some toxic substances, such as organic solvents and strong acids, are used in the production process. However, none of the workers showed excessive exposure to any of these substances in the regular monitoring of the workplace environment, workers' urine samples, or physical examinations conducted by occupational health physicians.

The traditional 8-hour shift in the factory had been conducted as a counterclockwise rotation, such as 5 days of daywork (0800-1630), 2 days off, 4 days of nightwork (0000-0815), 3 days off, and 5 days of evening work (1615-0015), and 2 days off. Dinner was served at 1930 on the evening shift, and a midnight meal was served at 0330 on the night shift. The 12 -hour shift introduced to the factory was composed of 2 weeks of day work (1000-2200) including 2 workdays, 2 days off, 3 workdays, 2 days off, 2 workdays, and 3 days off, and then 2 weeks of night work (2200-1000) in a similar way. Dinner was served at 1800 on the day shift, and a midnight meal and breakfast were served at 0045 and 0615 , respectively, on the night shift.
Almost all the shift workers in the factory had changed to 12-hour shifts in August 1997, but a few workers engaged in the production process remained on 8-hour shifts to maintain the efficacy of the process cycle, but not because of any preference of the workers. In our study, 192 men aged 21 to 47 years [mean 31.1 (SD 5.68) years] on 1 April 1996, who had been engaged in 8-hour shifts for 2 years or longer and who changed to 12-hour shifts and continued working 12hour shifts until September 1999 were targeted as the study subjects. Seventeen men aged 27 to 38 years [mean 32.8 (SD 4.17) years], who had also been engaged in 8-hour shifts for more than 2 years before August 1997 and who continued working 8-hour shifts thereafter were regarded as the reference group.

Records of the health checks conducted for shift workers each half year from May 1996 to November 1998 were reviewed for the 192 changed workers and the 17 unchanged ones. The health checks contained a questionnaire survey for subjective symptoms and a physical examination by an occupational health physician. In addition, health checks for all the workers in this factory are conducted every September, including measurements of height, body weight, and blood pressure. Therefore, the height, body weight, and blood pressure in 1996 were those observed a year before the shift change, and those in 1997 were observed 1 month after the shift change. These health checks had all been performed in a room of the factory from 0900 to 1600 , namely, for workers when they were on the day workshift.

The questionnaire for subjective symptoms used in the health checks of the shift workers was developed by the Matsushita Science Center of Industrial Hygiene to cover 58 possible symptoms, from illness of the central and peripheral nervous system, circulatory and respiratory system, digestive system, musculoskeletal system, skin, eyes and some psychological problems. The workers were asked about frequent recognition of the symptoms during the last 2 months (yes or no response) at an interview conducted by experienced nurses. Among the 58 items, 6 physical and 6 psychological ones, which had often been cited in the questionnaires for researching work-related fatigue in Japan $(2,3)$, were selected and defined as those related to fatigue in the present study. Low-back pain, stiff shoulder, joint pain, limb pain, dimmed sight, and sore throat were selected as the physical symptoms, and poor sleep, head heaviness, diminished alertness, tiredness, irritation, and unwillingness to go to the workplace were selected as the psychological ones. Chronbach's alpha coefficient was calculated for the evaluation of the internal reliability of the 12 subjective symptoms related to fatigue.

Height and weight were measured in the health checks with shoes and jackets removed. Blood pressure 
was measured using an automatic sphygmomanometer with an adequate size cuff on the right arm at heart level with the worker in a sitting position after resting on a chair for five minutes or longer.

Some of the subjects were receiving medication for hypertension or diabetes mellitus, but no worker had quit or stopped shift work due to illness or poor adaptation to the job during the observation period from May 1996 to September 1999. One man each in the 12-hour and 8-hour shift groups were omitted from the analyses because they had lost $10 \mathrm{~kg}$ or more of body weight in a year by special dieting. Two other men on the 12-hour shift were omitted because of incomplete records. Therefore, the data on the subjective symptoms, height, weight, and blood pressure of 189 workers on the 12hour shift and 16 on the 8-hour shift were subjected to the analyses.

The means of the counts of the subjective symptoms and those related to fatigue and the means of body weight $(\mathrm{kg})$, body mass index $(\mathrm{BMI}=$ weight in kilograms / height in square meters), and systolic and diastolic blood pressure (millimeters of mercury) during a year or longer before and after the change from 8-hour to 12hour shifts for the 189 workers were compared between two consecutive measurements and statistically tested by a paired t-test. The statistical analyses were also conducted for 16 workers who remained on 8-hour shifts. In addition, the differences in the changes in subjective symptoms, body weight, BMI and blood pressure over time between the 12-hour and 8-hour shift workers and between the younger and the older workers on the 12 hour shifts during the 3-year observation period were tested by a repeated-measure analysis of variance (ANOVA). Correlations between the counts of subjective symp- toms, BMI, and blood pressure at each health check and between the changes before and after the shift change were also calculated.

An SAS (statistical analysis system) program package for personal computers was used for calculating Cronbach's alpha coefficient, and the other statistical analyses were performed using a package of StatView 5.0 for Windows; both packages were provided by the SAS Institute, in the United States. Statistical significance was defined as $\mathrm{P}<0.05$. $\mathrm{P}<0.01$ was regarded as high significance and $0.05 \leq \mathrm{P}<0.10$ as borderline significance.

\section{Results}

Tables 1 and 2 show the prevalence of the six physical and six psychological symptoms that we considered to be related to fatigue among the 189 12-hour shift workers and the 16 8-hour shift workers during the six health checks conducted from May 1996 to November 1998. Cronbach's alpha coefficient for the 12 symptoms was calculated for the data from May 1997, before the shift change, and for those from November 1997, after the change. The obtained figures of 0.55 and 0.58 , respectively, were obviously not sufficiently high for a standard questionnaire but were above the minimum acceptable level of 0.5 for practical use (4).

Table 1 shows that the complaint of stiff shoulder was found for $7.4 \%$ to $7.9 \%$ of the 12 -hour shift workers before the shift change, but increased to $11.1 \%$ to $16.9 \%$, a roughly 1.5 -fold increase, thereafter. It was difficult, however, to detect marked increases in other

Table 1. Prevalence of six physical and six psychological symptoms defined to relate to fatigue for the 189 workers who had changed to a 12-hour shift from an 8-hour shift in August 1997.

\begin{tabular}{|c|c|c|c|c|c|c|c|c|c|c|c|c|}
\hline \multirow{2}{*}{$\begin{array}{l}\text { Symptoms related } \\
\text { to fatigue }\end{array}$} & \multicolumn{2}{|c|}{ May 1996} & \multicolumn{2}{|c|}{ November 1996} & \multicolumn{2}{|c|}{ May 1997} & \multicolumn{2}{|c|}{ November 1997} & \multicolumn{2}{|c|}{ May 1998} & \multicolumn{2}{|c|}{ November 1998} \\
\hline & $\mathrm{N}$ & $\%$ & $\mathrm{~N}$ & $\%$ & $\mathrm{~N}$ & $\%$ & $\mathrm{~N}$ & $\%$ & $\mathrm{~N}$ & $\%$ & $\mathrm{~N}$ & $\%$ \\
\hline \multicolumn{13}{|l|}{ Physical } \\
\hline Low-back pain & 17 & 9.0 & 22 & 11.6 & 23 & 12.2 & 19 & 10.0 & 24 & 12.7 & 18 & 9.6 \\
\hline Stiff shoulder & 15 & 7.9 & 14 & 7.4 & 15 & 7.9 & 21 & 11.1 & 32 & 16.9 & 23 & 12.2 \\
\hline Sore throat & 2 & 1.1 & 4 & 2.1 & 6 & 3.2 & 3 & 1.6 & 5 & 2.6 & 5 & 2.6 \\
\hline Dimmed sight & 6 & 3.2 & 5 & 2.6 & 6 & 3.2 & 8 & 4.2 & 5 & 2.6 & 5 & 2.6 \\
\hline Joint pain & 4 & 2.1 & 2 & 1.1 & 0 & & 3 & 1.6 & 2 & 1.1 & 3 & 1.6 \\
\hline Limb pain & 3 & 1.6 & 2 & 1.1 & 3 & 1.6 & 4 & 2.1 & 3 & 1.6 & 5 & 2.6 \\
\hline \multicolumn{13}{|l|}{ Psychological } \\
\hline Poor sleep & 7 & 3.7 & 6 & 3.2 & 5 & 2.6 & 13 & 6.9 & 15 & 7.9 & 14 & 7.4 \\
\hline Head heaviness & 3 & 1.6 & 3 & 1.6 & 4 & 2.1 & 9 & 4.8 & 9 & 4.8 & 8 & 4.2 \\
\hline Diminished alertness & 4 & 2.1 & 1 & 0.5 & 3 & 1.6 & 15 & 7.9 & 7 & 3.7 & 9 & 4.8 \\
\hline Tiredness & 2 & 1.1 & 3 & 1.6 & 3 & 1.6 & 1 & 0.5 & 5 & 2.6 & 5 & 2.6 \\
\hline Irritation & 3 & 1.6 & 1 & 0.5 & 3 & 1.6 & 4 & 2.1 & 1 & 0.5 & 4 & 2.1 \\
\hline $\begin{array}{l}\text { Unwillingness to go to } \\
\text { workplace }\end{array}$ & 1 & 1.1 & 3 & 1.6 & 3 & 1.6 & 7 & 3.7 & 8 & 4.2 & 10 & 5.3 \\
\hline
\end{tabular}


physical symptoms, although a slight increase was observed for some of them. On the other hand, almost all of the six psychological symptoms showed apparent increases after the change to 12-hour shifts. Particularly, poor sleep, head heaviness, diminished alertness, and unwillingness to go to the workplace increased twofold or more among the 12-hour shift workers. As shown in table 2, the workers who remained on 8-hour shifts did not show marked changes in either the physical or psychological symptoms during the six health checks.

Table 3 shows the mean counts for the subjective symptoms in the six health checks: those when counting a total of 58 items and those when counting 6 phys- ical and 6 psychological items related to fatigue, together with the standard deviations, for all the workers on 12-hour shifts and also the subgroups divided by decade of age such as the 20-year-olds, the 30-year-olds, and the 40-year-olds. The mean counts of the total number of symptoms for the 12-hour shift workers as a whole were less than 0.9 before the shift change but increased to 1.0 or above afterwards. Those for the physical and psychological symptoms related to fatigue were 0.28 and 0.11 or below, respectively, before the shift change, and they increased to 0.31 and 0.24 or above, respectively, afterwards. Similar changes were observed in all the three age groups of 20-year-olds, 30-year-olds,

Table 2. Prevalence of six physical and six psychological symptoms defined to relate to fatigue for the 16 workers who continued to work an 8-hour shift.

\begin{tabular}{|c|c|c|c|c|c|c|c|c|c|c|c|c|}
\hline \multirow{2}{*}{$\begin{array}{l}\text { Symptoms related } \\
\text { to fatigue }\end{array}$} & \multicolumn{2}{|c|}{ May 1996} & \multicolumn{2}{|c|}{ November 1996} & \multicolumn{2}{|c|}{ May 1997} & \multicolumn{2}{|c|}{ November 1997} & \multicolumn{2}{|c|}{ May 1998} & \multicolumn{2}{|c|}{ November 1998} \\
\hline & $\mathrm{N}$ & $\%$ & $\mathrm{~N}$ & $\%$ & $\mathrm{~N}$ & $\%$ & $\mathrm{~N}$ & $\%$ & $\mathrm{~N}$ & $\%$ & $\mathrm{~N}$ & $\%$ \\
\hline \multicolumn{13}{|l|}{ Physical } \\
\hline Low-back pain & 1 & 6.3 & - & $\cdot$ & - & $\cdot$ & - & $\cdot$ & - & $\cdot$ & 1 & 6.3 \\
\hline Stiff shoulder & 2 & 12.5 & 2 & 12.5 & 3 & 18.8 & 2 & 12.5 & 1 & 6.3 & 2 & 12.5 \\
\hline Sore throat & - & $\cdot$ & - & $\cdot$ & - & . & - & $\cdot$ & - & $\cdot$ & - & $\cdot$ \\
\hline Dimmed sight & - & . & - & . & 1 & 6.3 & 2 & 12.5 & 2 & 12.5 & - & . \\
\hline Joint pain & - & . & - & . & 1 & 6.3 & - & $\cdot$ & - & $\cdot$ & - & . \\
\hline Limb pain & - & . & - & . & - & $\cdot$ & - & . & - & . & - & . \\
\hline \multicolumn{13}{|l|}{ Psychological } \\
\hline Poor sleep & 1 & 6.3 & - & . & - & . & - & . & - & . & - & . \\
\hline Head heaviness & 1 & 6.3 & - & . & 2 & 12.5 & - & . & - & . & 1 & 6.3 \\
\hline Diminished alertness & - & . & - & . & 1 & 6.3 & - & . & 1 & 6.3 & 1 & 6.3 \\
\hline Tiredness & - & . & - & . & - & . & - & . & 1 & 6.3 & 1 & 6.3 \\
\hline Irritation & 1 & 6.3 & - & . & 1 & 6.3 & 1 & 6.3 & - & . & 2 & 12.5 \\
\hline $\begin{array}{l}\text { Unwillingness to go to } \\
\text { workplace }\end{array}$ & 1 & 6.3 & - & . & 1 & 6.3 & 1 & 6.3 & - & . & 1 & 6.3 \\
\hline
\end{tabular}

Table 3. Changes in the counts of the subjective symptoms of the workers who had changed to a 12-hour shift from an 8-hour shift in August 1997.

\begin{tabular}{|c|c|c|c|c|c|c|c|c|c|c|c|c|}
\hline \multirow[b]{2}{*}{ Subjects } & \multicolumn{2}{|c|}{ May 1996} & \multicolumn{2}{|c|}{ November 1996} & \multirow{2}{*}{$\frac{\text { May }}{\text { Mean }}$} & 1997 & \multicolumn{2}{|c|}{ November 1997} & \multicolumn{2}{|c|}{ May 1998} & \multicolumn{2}{|c|}{ November 1998} \\
\hline & Mean & SD & Mean & SD & & SD & Mean & SD & Mean & SD & Mean & SD \\
\hline \multicolumn{13}{|l|}{ All subjects $(N=189)$} \\
\hline All 58 items & 0.85 & 1.90 & 0.79 & 1.84 & 0.88 & 1.77 & $1.09^{\dagger}$ & 1.90 & 1.18 & 1.95 & 1.08 & 2.12 \\
\hline Physical, 6 items & 0.25 & 0.67 & 0.26 & 0.63 & 0.28 & 0.65 & 0.31 & 0.64 & 0.38 & 0.69 & 0.31 & 0.65 \\
\hline Psychological, 6 items & 0.11 & 0.43 & 0.09 & 0.32 & 0.11 & 0.36 & $0.26^{\star *}$ & 0.61 & 0.24 & 0.62 & 0.27 & 0.75 \\
\hline \multicolumn{13}{|c|}{ Subgroup of 20 -year-olds $(\mathrm{N}=86$ ) } \\
\hline All 58 items & 0.73 & 2.06 & 0.69 & 1.60 & 0.67 & 1.67 & 0.84 & 1.59 & 1.04 & 2.03 & 0.87 & 2.24 \\
\hline Physical, 6 items & 0.22 & 0.62 & 0.26 & 0.60 & 0.30 & 0.69 & 0.31 & 0.67 & 0.34 & 0.70 & 0.28 & 0.61 \\
\hline Psychological, 6 items & 0.11 & 0.44 & 0.09 & 0.36 & 0.07 & 0.30 & $0.20^{\star}$ & 0.55 & 0.17 & 0.56 & 0.22 & 0.80 \\
\hline \multicolumn{13}{|c|}{ Subgroup of 30 -year-olds $(\mathrm{N}=88$ ) } \\
\hline All 58 items & 0.82 & 1.62 & 0.84 & 1.99 & 1.06 & 1.79 & 1.23 & 1.94 & 1.31 & 1.88 & 1.22 & 2.05 \\
\hline Physical, 6 items & 0.18 & 0.47 & 0.26 & 0.67 & 0.26 & 0.65 & 0.28 & 0.59 & $0.40^{\dagger}$ & 0.67 & 0.30 & 0.68 \\
\hline Psychological, 6 items & 0.11 & 0.44 & 0.10 & 0.31 & 0.15 & 0.42 & $0.31^{\star}$ & 0.63 & 0.32 & 0.70 & 0.32 & 0.72 \\
\hline \multicolumn{13}{|c|}{ Subgroup of 40 -year-olds $(N=15)$} \\
\hline All 58 items & 1.73 & 2.37 & 1.07 & 2.22 & 1.07 & 2.22 & 1.67 & 2.99 & 1.20 & 1.94 & 1.47 & 1.84 \\
\hline Physical, 6 items & 0.80 & 1.37 & 0.27 & 0.59 & 0.27 & 0.46 & 0.40 & 0.74 & 0.47 & 0.74 & 0.53 & 0.74 \\
\hline Psychological, 6 items & 0.13 & 0.35 & 0.00 & 0.00 & 0.13 & 0.35 & 0.33 & 0.82 & 0.13 & 0.35 & 0.20 & 0.56 \\
\hline
\end{tabular}

$\dagger 0.05 \leq P<0.10,{ }^{\star} P<0.05,{ }^{* \star} P<0.01$ (statistically significant change from the preceding measure evaluated by a paired t-test). 
and 40-year-olds. A paired t-test for the difference in the counts between two consecutive health checks showed a significant increase in psychological symptoms between May 1997 and November 1997, just before and after the shift change, for all the 12-hour shift workers and for the subgroups of 20-year-olds and 30year-olds. A borderline significant increase was found for the total of symptoms among all the workers on 12hour shifts between May 1997 and November 1997 and for the physical symptoms of the 30-year-olds between November 1997 and May 1998.
The changes in the mean counts of the subjective symptoms of the 16 workers who remained on 8 -hour shifts are summarized in table 4. As shown, the mean counts of the symptoms varied considerably each time during the six health checks due to their small number. The mean counts of total symptoms, mainly for the 30year-olds, showed a significant decrease between May 1997 and November 1997. No significant changes were observed in the counts of symptoms related to fatigue.

Table 5 shows the means and standard deviations of body weight, BMI, and systolic and diastolic blood

Table 4. Changes in the counts of subjective symptoms of the workers who continued to work an 8-hour shift.

\begin{tabular}{|c|c|c|c|c|c|c|c|c|c|c|c|c|}
\hline \multirow[b]{2}{*}{ Subjects } & \multicolumn{2}{|c|}{ May 1996} & \multicolumn{2}{|c|}{ November 1996} & \multicolumn{2}{|c|}{ May 1997} & \multicolumn{2}{|c|}{ November 1997} & \multicolumn{2}{|c|}{ May 1998} & \multicolumn{2}{|c|}{ November 1998} \\
\hline & Mean & SD & Mean & SD & Mean & SD & Mean & SD & Mean & SD & Mean & SD \\
\hline \multicolumn{13}{|l|}{ All subjects $(N=16)$} \\
\hline All 58 items & 0.94 & 2.29 & 0.31 & 0.60 & 1.63 & 3.76 & $1.13^{\star}$ & 3.00 & 1.00 & 2.03 & 1.06 & 1.91 \\
\hline Physical, 6 items & 0.19 & 0.54 & 0.13 & 0.34 & 0.31 & 0.60 & 0.25 & 0.68 & 0.19 & 0.54 & 0.19 & 0.54 \\
\hline Psychological, 6 items & 0.25 & 0.68 & 0.0 & $\cdot$ & 0.31 & 1.01 & 0.13 & 0.50 & 0.13 & 0.50 & 0.38 & 1.03 \\
\hline \multicolumn{13}{|c|}{ Subgroup of 20-year-olds ( $N=4$ ) } \\
\hline All 58 items & 0.0 & . & 0.25 & 0.50 & 0.0 & . & 0.0 & . & 0.0 & . & 1.00 & 1.41 \\
\hline Physical, 6 items & 0.0 & . & 0.0 & $\cdot$ & 0.0 & . & 0.0 & . & 0.0 & . & 0.25 & 0.50 \\
\hline Psychological, 6 items & 0.0 & . & 0.0 & . & 0.0 & . & 0.0 & . & 0.0 & . & 0.25 & 0.50 \\
\hline \multicolumn{13}{|c|}{ Subgroup of 30 -year-olds $(\mathrm{N}=12)$} \\
\hline All 58 items & 1.25 & 2.60 & 0.33 & 0.65 & 2.17 & 4.24 & $1.50^{\star}$ & 3.43 & 1.33 & 2.27 & 1.08 & 2.11 \\
\hline Physical, 6 items & 0.25 & 0.62 & 0.17 & 0.39 & 0.42 & 0.67 & 0.33 & 0.78 & 0.25 & 0.62 & 0.17 & 0.58 \\
\hline Psychological, 6 items & 0.33 & 0.78 & 0.0 & 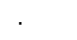 & 0.42 & 1.17 & 0.17 & 0.58 & 0.17 & 0.58 & 0.42 & 1.17 \\
\hline
\end{tabular}

$\dagger 0.05 \leq P<0.10,{ }^{*} P<0.05,{ }^{*} P<0.01$ (statistically significant change from the preceding measure evaluated by a paired $t$-test).

Table 5. Changes in body weight, body mass index (BMI), and blood pressure (BP) among the workers who had changed to a 12-hour shift from an 8-hour shift in August 1997.

\begin{tabular}{|c|c|c|c|c|c|c|c|c|}
\hline \multirow[b]{2}{*}{ Subjects } & \multicolumn{2}{|c|}{ September 1996} & \multicolumn{2}{|c|}{ September 1997} & \multicolumn{2}{|c|}{ September 1998} & \multicolumn{2}{|c|}{ September 1999} \\
\hline & Mean & SD & Mean & SD & Mean & SD & Mean & SD \\
\hline \multicolumn{9}{|l|}{ All subjects $(N=189)$} \\
\hline Body weight (kg) & 66.6 & 9.8 & 66.6 & 10.2 & $67.6^{\star \star}$ & 10.8 & 67.5 & 10.8 \\
\hline $\mathrm{BMI}\left(\mathrm{kg} / \mathrm{m}^{2}\right)$ & 22.9 & 3.2 & 22.8 & 3.4 & $23.2^{\star *}$ & 3.5 & 23.1 & 3.5 \\
\hline Systolic BP (mmHg a) & 121 & 11 & $127^{\star \star}$ & 12 & $124^{\star \star}$ & 11 & $122^{\star}$ & 12 \\
\hline Diastolic BP (mm Hg a) & 70.1 & 8.5 & $71.6^{\star \star}$ & 9.4 & 71.9 & 8.6 & $70.5^{\star \star}$ & 8.2 \\
\hline \multicolumn{9}{|c|}{ Subgroup of 20-year-olds ( $N=86$ ) } \\
\hline Body weight $(\mathrm{kg})$ & 65.9 & 10.3 & 65.8 & 10.7 & $67.0^{\star \star}$ & 11.7 & 67.2 & 11.6 \\
\hline BMI $\left(\mathrm{kg} / \mathrm{m}^{2}\right)$ & 22.1 & 3.3 & 22.0 & 3.4 & $22.4^{\star \star}$ & 3.7 & 22.5 & 3.7 \\
\hline Systolic BP (mm Hg $\left.{ }^{\mathrm{a}}\right)$ & 120 & 12 & $126^{\star *}$ & 12 & $123^{\star \star}$ & 11 & $120^{*}$ & 12 \\
\hline Diastolic BP (mm Hg a) & 67.5 & 8.9 & $69.7^{\star \star}$ & 8.7 & 70.2 & 8.3 & $68.1^{\star \star}$ & 8.1 \\
\hline \multicolumn{9}{|c|}{ Subgroup of 30 -year-olds $(\mathrm{N}=88$ ) } \\
\hline Body weight $(\mathrm{kg})$ & 67.4 & 9.6 & 67.5 & 10.0 & $68.4^{\star \star}$ & 10.3 & 68.2 & 10.6 \\
\hline BMI $\left(\mathrm{kg} / \mathrm{m}^{2}\right)$ & 23.4 & 3.2 & 23.4 & 3.4 & $23.7^{\star \star}$ & 3.4 & 23.6 & 3.4 \\
\hline Systolic BP (mm Hg a) & 122 & 10 & $128^{\star *}$ & 12 & $124^{*}$ & 12 & 123 & 12 \\
\hline Diastolic BP (mm Hg $\left.{ }^{\mathrm{a}}\right)$ & 71.6 & 7.5 & 72.5 & 9.1 & 72.9 & 8.4 & 72.0 & 7.4 \\
\hline \multicolumn{9}{|c|}{ Subgroup of 40 -year-olds $(N=15)$} \\
\hline Body weight $(\mathrm{kg})$ & 65.9 & 7.9 & 66.3 & 7.9 & 67.0 & 7.9 & 65.7 & 7.1 \\
\hline BMI $\left(\mathrm{kg} / \mathrm{m}^{2}\right)$ & 23.7 & 2.6 & 23.8 & 2.6 & 24.0 & 2.5 & 23.6 & 2.0 \\
\hline Systolic BP (mm Hg a) & 124 & 11 & 127 & 13 & 123 & 13 & 125 & 11 \\
\hline Diastolic BP (mm Hg a) & 75.6 & 6.2 & 77.6 & 12.3 & 76.4 & 9.5 & 75.9 & 8.9 \\
\hline
\end{tabular}

a $1 \mathrm{~mm} \mathrm{Hg} \approx 0.133 \mathrm{kPa}$.

$\dagger 0.05 \leq P<0.10,{ }^{*} P<0.05,{ }^{* *} P<0.01$ (statistically significant change from the preceding measure evaluated by a paired t-test). 
pressure for the 189 workers on 12-hour shifts and those of the age subgroups from September 1996 to September 1999. The mean body weight for all the 12-hour shift workers was $66.6 \mathrm{~kg}$ in 1996, $66.6 \mathrm{~kg}$ in 1997, $67.6 \mathrm{~kg}$ in 1998 , and $67.5 \mathrm{~kg}$ in 1999 , showing a weight gain of $1.0 \mathrm{~kg}$ in the year between 1997 and 1998 (ie, between the beginning of and a year after the start of the 12-hour shift work). On the other hand, similar weights were observed in the years of 1996 and 1997 (in the year before the change) and also in 1998 and 1999 (1 to 2 years afterwards). Weight gain in the year between 1997 and 1998 was $1.2 \mathrm{~kg}$ for the 20 -year-olds and $0.9 \mathrm{~kg}$ for the 30 -year-olds. The 40 -year-olds showed a weight gain of $0.7 \mathrm{~kg}$ in the year between 1997 and 1998, but they showed a loss of $1.3 \mathrm{~kg}$ between 1998 and 1999. Altogether, they lost $0.2 \mathrm{~kg}$ of body weight from 1996 to 1999. A paired t-test for the change in body weight between two consecutive years showed a significant increase for all the 12-hour shift workers and also for the 20-year-olds and 30-year-olds between 1997 and 1998. Correspondingly, the BMI of the workers on 12-hour shifts increased significantly from 22.8 to 23.2 for all the workers, 22.0 to 22.4 for the 20 -year-olds, and 23.4 to 23.7 for the 30 -year-olds between 1997 and 1998. The increase for the 40 -year-olds was from 23.8 to 24.0 , with a decrease to 23.6 in 1999.

On the other hand, the 16 workers on 8-hour shifts showed a large variation in mean body weight, namely, $67.0 \mathrm{~kg}$ in 1996, $66.5 \mathrm{~kg}$ in 1997, $67.1 \mathrm{~kg}$ in 1998 and $66.3 \mathrm{~kg}$ in 1999 (table 6). The 8-hour 20-year-olds showed a weight gain of $0.8 \mathrm{~kg}$ between 1997 and 1998, but they numbered only four. The 30-year-olds showed a weight gain of $0.2 \mathrm{~kg}$ between 1997 and 1998, but they showed a loss of $1.1 \mathrm{~kg}$ between 1998 and 1999. No statistically significant changes were found for either the entire 8-hour shift group or the age subgroups during 1996 and 1999. The changes in BMI among the subjects were not significant either.

As shown in tables 5 and 6 , the mean blood pressure varied markedly and often showed a statistically significant difference between two consecutive years, among both the 12-hour shift workers and the 8-hour shift workers. Thus the changes in blood pressure were thought to relate to some technical factors involved in the measurements, such as room temperature, noise, or equipment, rather than to the shift change.

Although the increases in symptoms, body weight, and BMI in the year between 1997 and 1998 seemed more conspicuous for the 12-hour shift workers in comparison with the 8-hour workers and the younger workers in comparison with the older workers on 12-hour shifts, the differences were not statistically significant in a repeated-measure ANOVA. The number of 8-hour shift workers and that of the 40-year-olds on 12-hour shifts were too small to test for statistical significance.

The correlation coefficients between BMI and systolic and diastolic blood pressure constantly ranged from 0.35 to 0.38 , being highly significant at each health check. The changes in the counts of subjective symptoms, BMI, and blood pressure before and after the shift change did not show significant correlations with each other.

Table 6. Changes in body weight, body mass index (BMI) and blood pressure (BP) among the workers who continued to work 8-hour shifts.

\begin{tabular}{|c|c|c|c|c|c|c|c|c|}
\hline \multirow[b]{2}{*}{ Subjects } & \multicolumn{2}{|c|}{ September 1996} & \multicolumn{2}{|c|}{ September 1997} & \multicolumn{2}{|c|}{ September 1998} & \multicolumn{2}{|c|}{ September 1999} \\
\hline & Mean & SD & Mean & SD & Mean & SD & Mean & SD \\
\hline \multicolumn{9}{|l|}{ All subjects $(\mathrm{N}=16)$} \\
\hline Body weight (kg) & 67.0 & 8.7 & 66.5 & 8.7 & 67.1 & 8.5 & 66.3 & 8.5 \\
\hline $\mathrm{BMI}\left(\mathrm{kg} / \mathrm{m}^{2}\right)$ & 22.8 & 2.1 & 22.6 & 2.1 & 22.8 & 2.0 & 22.6 & 2.0 \\
\hline Systolic BP (mm Hg ${ }^{\mathrm{a}}$ ) & 126 & 12 & $131^{*}$ & 12 & 127 & 10 & 124 & 10 \\
\hline Diastolic BP (mm Hg a) & 73.6 & 7.6 & 74.9 & 8.4 & 72.8 & 8.4 & 72.9 & 8.5 \\
\hline \multicolumn{9}{|c|}{ Subgroup of 20-year-olds $(\mathrm{N}=4)$} \\
\hline Body weight $(\mathrm{kg})$ & 69.5 & 10.8 & 68.9 & 12.1 & 70.7 & 12.1 & 71.0 & 10.1 \\
\hline $\mathrm{BMI}\left(\mathrm{kg} / \mathrm{m}^{2}\right)$ & 23.5 & 2.0 & 23.2 & 2.2 & 23.7 & 1.8 & 23.9 & 1.3 \\
\hline Systolic BP (mm Hg a) & 124 & 9 & 127 & 11 & 124 & 11 & 121 & 13 \\
\hline Diastolic BP (mm Hg $\left.{ }^{\mathrm{a}}\right)$ & 72.0 & 5.0 & 74.8 & 5.4 & 71.0 & 2.7 & 68.0 & 6.4 \\
\hline \multicolumn{9}{|c|}{ Subgroup of 30 -year-olds $(\mathrm{N}=12)$} \\
\hline Body weight (kg) & 66.2 & 8.2 & 65.7 & 7.7 & 65.9 & 7.2 & 64.8 & 7.8 \\
\hline $\mathrm{BMI}\left(\mathrm{kg} / \mathrm{m}^{2}\right)$ & 22.6 & 2.2 & 22.4 & 2.1 & 22.5 & 2.0 & 22.1 & 2.1 \\
\hline Systolic BP (mm Hg a) & 126 & 13 & $132^{\dagger}$ & 12 & 128 & 10 & 125 & 9 \\
\hline Diastolic BP (mm Hga $)$ & 74.1 & 8.5 & 74.9 & 9.4 & 73.3 & 9.6 & 74.5 & 8.7 \\
\hline
\end{tabular}

a $1 \mathrm{~mm} \mathrm{Hg} \approx 0.133 \mathrm{kPa}$.

$\dagger 0.05 \leq \mathrm{P}<0.10,{ }^{\star} \mathrm{P}<0.05,{ }^{\star *} \mathrm{P}<0.01$ (statistically significant change from the preceding measure evaluated by a paired t-test). 


\section{Discussion}

Considering the circumstances surrounding the implementation of the new 12-hour shift in the factory under study, such as the abolishment of the accustomed 8-hour shift and the introduction of a previously inexperienced longer work period to the workforce, as well as concern about an excessive workload by the workers' union, we analyzed the data of routine periodic health checks. Since the workers were not aware of this use of the data to evaluate the effects of the new shift on their health, the influence of an intentional attitude toward the new shift may have been reduced or avoided, at least to some degree. The observation was done not only for the data just before and after the shift change but also for those from a year or longer earlier and later, which also helps to avoid the so-called honeymoon or Hawthorne effect during the period of adaptation to the new shift. Furthermore, we are confident that no important information on the health effects of the new shift system was missed since no workers quit or stopped shift work because of ill health or poor adaptation to it during the observation period.

The 58 items in the questionnaire covered symptoms reflecting illness originating in various organs and systems. Although the means for the 58 symptoms of the 12-hour shift workers showed a borderline significant increase before and after the shift change, the major symptoms related to serious circulatory or digestive illness, such as chest pain, palpitation, shortness of breath, abdominal pain, anorexia, nausea and vomiting, were rare both before and after the shift change, and they did not increase with the 12-hour shift work. Together with the fact that no workers quit or stopped shift work, we concluded that no serious health problems occurred among the workers after changing to the 12-hour shift. Only minor ocular symptoms, such as light pain, itchy and uncomfortable feeling in the eyes, and nasal discharge were slightly increased after the change.

On the other hand, the symptoms that we considered to reflect fatigue psychologically were increased markedly after the shift change; particularly, poor sleep, head heaviness, diminished alertness, and unwillingness to go to the workplace were increased twofold or more. These symptoms were generally rare, in 5 or so of the 189 workers when they were working 8-hour shifts, but increased to 10 or more with the 12 -hour shift work. The questionnaire was administered to the workers while they were on their day shift, and thus these symptoms did not reflect the acute effects of night work but, rather, reflected more chronic effects of 12-hour shift work. The increase in symptoms was still apparent even a year later. It can be said, therefore, that working 12-hour shifts caused psychologically marked fatigue in some of the cleanroom workers who had been accustomed to 8-hour shifts and that adaptation to the new workshift did not seem easy for them, although it might be possible in later years.

The effects of compressed work, like 12-hour shifts, on health and life have been investigated among workers in production industries (5-7), computer operating (8-10), a power station (11), police work (12), and nursing (13-16). Although many of the studies showed that 12-hour shifts, as compared with 8-hour shifts, have been generally less harmful to both the physical and psychological health of the worker and the family and social life of the workers, increased fatigue and decreased job performance have often been observed among nurses (13-15) or control room operators of a plant by Rosa et al $(8,9)$. Rosa et al thus pointed out that the fatiguing effect of the longer work period may be exacerbated by jobs that are sedentary, automated, or require relatively more cognitive, as opposed to physical activity (17). This must also be the case in jobs imposing a heavy physical and mental workload such as nursing (1).

Our workers did not handle heavy materials and did not need to perform strong physical actions, but they needed to walk around to operate and maintain the process machines. Detecting and repairing work for minor defects in the products using a video display apparatus may need considerable concentration but may not be a severe strain. So the jobs of our subjects were not typically sedentary, automated, or highly monotonous, although they were somewhat repetitious. The exacerbating factors for fatigue due to 12-hour shift work in this work population thus remain unclear.

Overtime, moonlighting, or responsibility for family and society are important factors contributing to fatigue among shift workers. Although we did not survey directly the effects of such factors on the complaints among the subjects, the average overtime of the workers was 4 to 5 hours per month, and it did not differ before and after the shift change. In addition, the family and social responsibilities were not thought to have changed significantly after the shift change. As far as we know, the subjects were unlikely to moonlight more frequently when on the 12-hour shifts. A negative attitude of the workforce in association with the implementation of the new shift, which we tried to avoid or reduce by analyzing routine data, may have had a bearing on the increases in complaints. According to a survey conducted by the labor union, the overall preference for the two shifts among the workers was almost equal, onethird preferring the 8-hour shift, one-third preferring the 12-hour shift, and the remaining third liking or disliking the two shifts equally. The influence of the shift preference on the subjective symptoms remains to be elucidated by further studies.

Stress at work is another important factor causing worker fatigue. It would thus be likely that daily 
nuisances associated with working in a clean room, such as wearing special clothes, cap, mask, gloves, and shoes and passing air shower gates whenever entering the workplace, may have constituted a strong stressor and exacerbated fatigue at work. Although it is difficult to determine the major factors related to the excessive fatigue among our subjects, working in a clean room could be listed as a job in which special caution for increased fatigue is needed when a compressed work schedule is implemented.

Efforts should be focused, therefore, on reducing fatigue among cleanroom workers who work a compressed schedule. It has been recommended that shift systems in a compressed workweek be designed to minimize the accumulation of fatigue and that quickly rotating systems are generally preferable to slowly rotating ones (18). As a case for cleanroom workers, Toyoda $\&$ Yamada (19) reported the reduction of acute fatigue complaints related to daily 12-hour operation after the rotation was revised from a 2 -week slow daynight rotation, which was done for our subjects, to a 2or 3-day quick day-night rotation (ie, 2 days of work, 2 days off, 3 nights of work, 2 days off, 2 days of work, 3 days off, etc) in a plant producing electronic semiconductors. Thus a quick rotating system should be implemented in this factory and evaluated for any improvements in chronic fatigue by a further study. Such a revision of the shift schedule has been discussed in this factory, but no consensus has yet been reached among the workers or between the company and the workforce. Improvements in operational and environmental conditions have also been instituted in this factory, but, as shown in the study results, they have not yet succeeded in reducing fatigue.

Another conspicuous finding in this study was weight gain, $1 \mathrm{~kg}$ in a year, among the subjects after they started working 12-hour shifts. The weight gain seemed more marked among the younger workers in their 20 s or 30 s than among the older ones in their 40 s, although the differences did not reach statistical significance. To our knowledge, unhealthy weight gain has not been well documented as a health effect of 12-hour shift work. However, Nakata et al (20) similarly observed weight gain among workers in an electronic parts factory, an average of $1 \mathrm{~kg}$ in a year, after implementing 12-hour shift work instead of the traditional 8-hour shift. They did not confirm the findings by repeated or long-term observation, but, as shown in our study, the increased weight persisted even after another year. There have been some studies implicating night shift work itself as a cause of weight gain (21-23). The exact mechanisms of weight gain due to night shift work have remained obscure, but excessive food intake, particularly at night (night eating), reduced energy consumption in daytime (more and longer naps), and dis- turbances in the circadian rhythm of hormonal excretion have been proposed.

Exact data on the changes in the life of our subjects after they started 12-hour shift work were not available, but, in the interviews conducted by the nurses in the health checks, some of the workers admitted to additional intake of foods or alcoholic beverages after returning home and before going to bed to promote a quick sleep. In addition, some of them tended to sleep longer, particularly on the first off-duty day after night work. Although increased family or social activity in the longer off-duty time is the most expected benefit of the compressed work schedule, some workers may spend these days in a sedentary fashion, resulting in a reduction in total energy consumption. The sedentariness in off-duty time may reflect a need for recuperation from the excessive fatigue due to 12-hour shift work, as was suggested in a study on nurses working 12-hour shifts (24). However, the association between increased fatigue and weight gain was obscure among our subjects since no significant correlations were found between the increases in fatigue symptoms and those in body weight after the shift change.

The older workers in their 40s among our subjects showed a loss of weight after another year, while a temporary weight gain was observed in the year after they started 12-hour shift work. Older workers are generally much more concerned about their own health than younger ones. Therefore, the increased body weight of the younger workers in their 20 s and 30 s could also return to the levels observed while they were on 8-hour shifts in later years as they adapt their life style to the new shift. However, if increased body weight remains high even years later, it may exert considerable deleterious effects on the health of the workers. According to epidemiologic studies on the Japanese population, the ideal BMI with the lowest morbidity has been proposed to be $22.2 \mathrm{~kg} / \mathrm{m}^{2}$ for men (25), a value which is lower than the average of our subjects, and an increase of 1.0 $\mathrm{kg} / \mathrm{m}^{2}$ in BMI corresponds to $37 \%$ and $26 \%$ increases in the odds of hypertension and high blood cholesterol, respectively, for men aged 30-39 years, for whom the BMI ranged from 20.0 to 26.0 , and thus were not obese (26).

Blood pressure correlated strongly with the BMI of our subjects every year. Therefore, although no significant change in blood pressure was observed after the move to 12-hour shifts, an elevation of blood pressure may be revealed by repeated and longer observations of the subjects who gained weight. An association of shift work, although it was 8-hour shift work, with the onset of hypertension was suggested in a study for a male Japanese occupational population (27).

The adverse health effects of increased body weight are even more serious for workers when they have 
hypertension or diabetes mellitus. Some of our subjects were indeed under medication for hypertension and diabetes. Much attention, therefore, should be paid to possible weight gain after a compressed work schedule is implemented. According to a survey in this factory, only $5 \%$ of the male workers performed physical exercise regularly twice a week or more. Therefore, the workers should be encouraged to increase their physical activity and maintain moderate food intake, particularly in the long off-duty time, in order to maintain body weight and health. Regular physical exercise has been reported to improve the quality of sleep (28) and even psychological health (29-31) and thus may also be helpful in reducing work-related fatigue (32), together with improvements in shift schedules and other work conditions.

\section{References}

1. Smith L, Folkard S, Tucker P, Macdonald I. Work shift duration: a review comparing eight hour and 12 hour shift systems. Occup Environ Med 1998;55:217-29.

2. Saito Y. Feeling of fatigue. In: The Committee of Research on Work-related Fatigue in Japan Society for Occupational Health, editors. Handbook for fatigue at work. Tokyo: Working Standard Research Association, 1995:164.

3. Kosugou R. Survey on symptoms in accumulated fatigue. In: Kogi K, editor. Survey on workload. Kawasaki: Institute for Science of Labor, 1984:173.

4. Iwasaki S. Science in psychometrical tests. In: Okado T, editor. Psychometrical tests: fundamentals of psychological assessment. Tokyo: Kakiuchi Shuppan Co, 1975:28.

5. Frese M, Semmer N. Shiftwork, stress, and psychosomatic complaints: a comparison between workers in different shiftwork schedules, non-shiftworkers, and former shiftworkers. Ergonomics 1986;29:99-114.

6. Lees REM, Laundry BR. Comparison of reported workplace morbidity in 8-hour and 12-hour shifts in one plant. J Soc Occup Med 1989;39:81-4.

7. Tucker P, Barton J, Folkard S. Comparison of eight and 12 hour shifts: impacts on health, wellbeing, and alertness during the shift. Occup Environ Med 1996;53:767-72.

8. Rosa RR, Colligan MJ, Lewis P. Extended workdays: effects of 8-hour and 12-hour rotating shift schedules on performance, subjective alertness, sleep patterns, and psychosocial variables. Work Stress 1989;3:21-32.

9. Rosa RR. Performance, alertness, and sleep after 3.5 years of 12 h shifts: a follow-up study. Work Stress 1991;5:107-16.

10. Williamson AM, Gower CGI, Clarke BC. Changing the hours of shiftwork: a comparison of 8-and 12-hour shift rosters in a group of computer operators. Ergonomics 1994;37:287-98.

11. Mitchell RJ, Williamson AM. Evaluation of an 8 hour versus a 12 hour shift roster on employees at a power station. Appl Ergon 2000;31:83-93.

12. Peacock B, Glube R, Miller M, Clune P. Police officers' responses to 8 and 12 hour schedule. Ergonomics 1983; 26:479-93.

13. Mills ME, Arnold B, Wood CM. Core 12: a controlled study of the impact of 12-hour scheduling. Nurs Res 1983;32:35661.

14. Thompson J. Rigour round the clock. Nurs Times 1989; $85: 21$.

15. Iskra-Golec I, Folkard S, Marek T, Noworol C. Health, wellbeing and burnout of ICU nurses on 12- and 8-h shifts. Work Stress 1996;10:251-6.

16. Takahashi M, Fukuda H, Miki K, Haratani T, Kurabayashi L, Hisanaga N, et al. Shift work-related problems in 16-h night shift nurses (2): effects on subjective symptoms, physical activity, heart rate, and sleep. Ind Health 1999;37:228-36.

17. Rosa RR. Extended workshifts and excessive fatigue. J Sleep Res 1995;4 suppl 2:51-6.

18. Knauth P. The design of shift systems. Ergonomics 1993; $36: 15-28$.

19. Toyoda N, Yamada S. Stress in shift and night workers. Sangyo Eiseigaku Zasshi 2000;42:A33-4.

20. Nakata A, Oheda H, Kinoshita M. Effects of a change from a 3 -shift to a 2-shift work schedule on body weight. Matsushita Med J 2000;39:41-6.

21. Niedhammer I, Lert F, Marne MJ. Prevalence of overweight and weight gain in relation to night work in a nurses' cohort. Int J Obes 1996;20:625-33.

22. Van Amelsvoort LGPM, Schouten EG, Kok FJ. Duration of shiftwork related to body mass index and waist to hip ratio. Int J Obes 1999;23:973-8.

23. Geliebter A, Gluck ME, Tanowitz M, Aronoff NJ, Zammit GK. Work-shift period and weight change. Nutrition 2000;16:27-9.

24. Kundi M, Koller M, Stefan H, Lehner L, Kaindlsdorfer S, Rottenbucher S. Attitudes of nurses towards 8-h and 12-h shift systems. Work Stress 1995;2(3):134-9.

25. Tokunaga K, Matsuzawa Y, Kotani K, Keno Y, Kobatake T, Fujioka S, et al. Ideal body weight estimated from the body mass index with the lowest morbidity. Int J Obes 1991;15:15.

26. Yoshiike N, Yamaguchi M, Matsumura Y, Ohtani Y, Inoue $\mathrm{K}$, Kawano M, et al. Levels of obesity classified with BMI and the frequencies of the complications: re-analyses on the data of National Nutrition Survey. Himan Kenkyu (J Jpn Soc Study Obes) 1998;4 suppl 1: 5-11.

27. Morikawa $Y$, Nakagawa H, Miura K, Ishizaki M, Tabata M, Nishijo M, et al. Relationship between shift work and onset of hypertension in a cohort of manual workers. Scand J Work Environ Health 1999;25:100-4.

28. Sasazawa Y, Ogawa M, Kawada T, Suzuki S, Duki, MIZ. Afternoon exercise improves the quality of night sleep: a case study observed by EEG and self-rating scale. J Occup Health 1998;40:37-43.

29. Farmer ME, Locke BZ, Mosciki EK, Dannenberg AL, Larson DB, Radloff LS. Physical activity and depressive symptoms: the NHSNES I epidemiologic follow-up study. Am J Epidemiol 1988;128:1340-51.

30. Camacho TC, Roberts RE, Lazarus NB, Kaplan GA, Cohen RD. Physical activity and depression: evidence from the Alameda County Study. Am J Epidemiol 1991;134:220-31.

31. Paffenbarger RS, Lee IM, Leung R. Physical activity and personal characteristics associated with depression and suicide in American college men. Acta Psychiatr Scand Suppl 1994;377:16-22.

32. Härmä M. Aging, physical fitness and shiftwork tolerance. Appl Ergon 1996;27:25-9.

Received for publication: 19 March 2001 